Review Article

\title{
Ultrasound for Women's Pelvic Floor Dysfunction
}

\section{Selina Man Wah Pang}

Department of Obstetrics and Gynecology, Prince of Wales Hospital, Hong Kong, China

Correspondence: Selina Man Wah Pang, Department of Obstetrics and Gynecology, Prince of Wales Hospital, Block 1E Shatin, NT Hong Kong, SAR China, Phone: 852-26322810, Fax: 852-26360008, e-mail: Selina.Pang@gmail.com

\begin{abstract}
The advent of ultrasound and more recently three-dimensional ultrasound enables evaluation of functional anatomy of women's pelvic floor disorders. The observations in women's pelvic floor ultrasound showed that it is a promising modality not only in research but also clinical applications for the management of women's pelvic floor disorders in the future.

Keywords: Ultrasound, pelvic floor disorders.
\end{abstract}

\section{INTRODUCTION}

In the past, clinicians managing female pelvic floor disorders focused on functional assessment using urodynamics studies and urethral pressure profilometry. Anatomical assessment was made by clinical examination alone. Under special conditions when an imaging technique for anatomical assessment of the female pelvic floor disorder is perceived necessary, contrast X-ray techniques is used., ${ }^{1,2}$ The complexity of the setup for these procedures and the risk of radiation exposure limits its routine clinical application.

The advent of ultrasonography (USG) and magnetic resonance imaging (MRI) enable clinicians to have a safe and convenient tool to assess female pelvic floor disorders. The new tools provide a better assessment of soft tissue support (the primary event in pelvic floor trauma) in the female pelvic floor compared to contrast X-ray. USG has the added advantage of being a standard piece of office equipment in gynecological practice which makes it an inexpensive and extremely convenient tool to use. Real-time assessment using USG is able to delineate functional anatomy of female pelvic floor disorders.

To date, USG assessment of female pelvic floor disorders is not yet used in routine clinical practice. However, researches using USG unveiled a number of functional anatomical phenomenon in women's pelvic floor disorders, such as trauma to pelvic floor in childbirth, the mechanism of female continence, the mechanics of how tension free vaginal tape (TVT) works and the anatomical reasons for why some TVT procedures failed. ${ }^{3-5}$ It is also a statistically more sensitive tool to assess outcomes after intervention compared to clinical examination alone.

\section{METHODOLOGY}

A mid-sagittal view is obtained by placing a transducer (3.5$7 \mathrm{MHz}$ curved array) on the perineum of women. ${ }^{6}$ Trans labial USG is usually performed in a dorsal lithotomy position with the women's hips flexed and slightly abducted. The transducer is in close approximation with the perineum after parting the labia without pressure to distort the anatomy. A standard image of assessment should be obtained which includes the following structures: symphysis pubis, urethra, bladder neck, the vagina, cervix, rectum and anal canal. Most of the information of Translabial USG is obtained from the mid-sagittal plane.

\section{PARAMETERS OF ASSESSMENT}

\section{Bladder Neck Mobility}

Bladder neck mobility and position is the most thoroughly investigated parameter in Translabial USG of women's pelvic floor. Measurements are performed at rest and on valsalva maneuver. Measurements are made with reference to the symphysis pubis. Parameters which we can measure include: bladder neck descend, posterior urethrovesical angle between proximal urethra and trigone or the angle between the central axis of symphysis pubis and a line from the inferior symphyseal margin to the bladder neck. Of these measurements, bladder neck descend has the best reproducibility. ${ }^{7}$

\section{Funnelling of Internal Urethral Meatus}

Funnelling of internal urethral meatus could be observed in women with stress urinary incontinence and also in asymptomatic women. However, marked funnelling was associated with low urethral closure pressures. ${ }^{8,9}$

\section{Pelvic Organ Prolapse Quantification}

The symphysis pubis can be used as a line of reference upon which descent of the bladder, uterus, cul-de-sac and rectal 
ampulla can be measured upon valsalva maneuver. This method is shown to have good correlation with clinical pelvic organ prolapse staging for the anterior and central compartment. ${ }^{10}$

\section{Evaluation of Mesh Implant}

The success of tension free vaginal tape (TVT) for the treatment of women's stress urinary incontinence leads to a plethora of synthetic mesh surgical implants for the treatment of women's stress urinary incontinence (SUI) and pelvic organ prolapse. The prolene weave meshes are easily visualized with USG. Despite the clinical observation of a high success rate for SUI control with TVT, it was not until imaging with USG which explained the mechanics of how TVT control SUI. During a valsalva, the tape compresses a women's urethra against the symphysis pubis which makes her continent. ${ }^{5}$ Among women who had TVT, the position of TVT varied a lot but more cranial tapes were associated with more voiding difficulty, de novo urgency and failure to control SUI. ${ }^{3}$

\section{THREE-DIMENSIONAL ULTRASOUND}

Whilst conventional two dimensional USG is a useful and reproducible tool to evaluate the anterior and central compartment of a women's pelvic floor, its inability to access the axial plane of the female pelvic floor limits it's use in the assessment of levator ani muscles and lateral support of the vagina, which is believed to be fundamental to pelvic floor trauma.

With motorized acquisition, axial plane assessment of the female pelvic floor is made possible with a threedimensional Translabial USG. The standard mid-sagittal orientation is obtained for volume data acquisition. With an acquisition angle of more than 70 degree, the entire levator hiatus, symphysis pubis, urethra, paravaginal tissues, the vagina, anorectum and puborectalis, arcus tendineous of the levator ani and the posterior aspect of the anorectal junction are visualized.

\section{Assessment of Levator Ani Complex}

Assessment of the axial plane enables visualization of the levator hiatus complex. Morphometric assessment of the levator muscles enables visualization of levator muscle avulsion in childbirth. ${ }^{11}$ Hiatal area measurements were highly reproducible and correlated strongly with pelvic organ descent. ${ }^{11}$

Another advantage of three-dimensional USG is the functional assessment of levator ani muscles. The resting tone of levator ani muscles were found to be associated with the levator hiatal area at rest, at valsalva and the area of levator ani muscles complex. ${ }^{12}$ Both the hiatal area at rest and hiatal area at valsalva were correlated with symptoms of pelvic organ prolapse. ${ }^{13}$

\section{CONCLUSION}

USG assessment of women's pelvic floor disorder is a safe, convenient new modality in assessing the functional anatomy of pelvic floor disorders. Observational researches explained a number of phenomena in the development of pelvic floor disorders. It is also an invaluable tool in researches in women's pelvic floor disorders as it is a statistically sensitive tool to detect differences and changes in pelvic floor parameters.

\section{REFERENCES}

1. Hogdkinson C. Relationships of the female urethra and bladder in urinary incontinence. Am J Obstet Gynecol 1953;65:560-73.

2. Jeffcoate $\mathrm{T}$, Roberts $H$. Observations on stress incontinence of urine. Am J Obstet Gynecol 1952;64:721-38.

3. Dietz H, Mouritsen L, Ellis G. Wilson P. How important is TVT location? Acta Obstetricia et Gynecologica Scandinavica 2004;83:904-08.

4. Dietz H, Schierlitz L. Pelvic floor trauma in childbirth - myth or reality? ANZJOG 2005;45:3-11.

5. Dietz H, Wilson P. The 'iris effect': How two-dimensional and three-dimensional ultrasound can help us understand antiincontinence procedures. Ultrasound in Obstetrics and Gynecology 2004;23:267-71.

6. Dietz H. Ultrasound imaging of the pelvic floor. Part I. twodimensional aspects. Ultrasound Obstet Gynecol 2003;23: 80-92.

7. Dietz H, Steensma A, Eldridge A. Reliability of ultrasound assessment of bladder neck mobility. International Urogynecological Association, 2007.

8. Dietz H, Clarke B. The urethral pressure profile and ultrasound imaging of the lower urinary tract. Int Urogynecol J 2001;12: 38-41.

9. Huang W, Yang J. Bladder neck funneling on ultrasound cystourethrography in primary stress urinary incontinence: A sign associated with urethral hypermobility and intrinsic sphincter deficiency. Urology 2003;61:936-41.

10. Dietz H, Haylen B, Broome J. Ultrasound in the quantification of female pelvic organ prolapse. Ultrasound Obstet Gynecol 2001;18:511-14.

11. Shek K, Dietz H, Eldridge A. Biometry of the puborectalis muscle and levator hiatus. Conference proceedings, ISUOG Joint Scientific Meeting, Singapore 2004.

12. Dietz H, Shek K. The quantification of levator muscle resting tone by digital assessment. Int Urogynecol J 2008;19:1489-93.

13. Leon J, Steensma A, Shek K, Dietz H. Ballooning: How to define abnormal distensibility of the levator hiatus. Ultrasound Obstet Gynecol 2007;30:455. 